\title{
Reaction kinetics of ethane partial oxidation to acetic acid
}

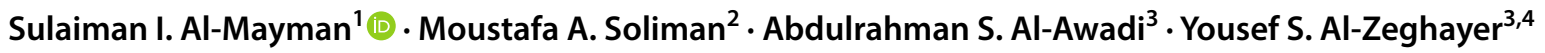

Received: 6 February 2018 / Accepted: 13 February 2018 / Published online: 7 March 2018

(c) The Author(s) 2018. This article is an open access publication

\begin{abstract}
The partial oxidation of ethane to ethylene and acetic acid on supported $\mathrm{MoVNbPd} / \mathrm{TiO}_{2}(\mathrm{P} 25$ of Degussa) has been investigated. Pd was added in a nano-metallic form. The catalyst composition was also different from similar studied catalysts. This results in a better selectivity towards acetic acid formation. The reaction was carried out in a tubular reactor at temperature range $225-275^{\circ} \mathrm{C}$, total pressure range $0-200 \mathrm{psig}$ and oxygen percentage in the feed gas of $10-40 \%$. The feed gas contains ethane and oxygen. In this work, we develop a kinetic model for the reaction for the developed catalyst. In this model, we assume that oxidation reactions take place on different sites; ethane oxidation takes place on one site, ethylene oxidation on another site, and $\mathrm{CO}$ is oxidized to $\mathrm{CO}_{2}$ on a third site. The model exhibits good agreement with the experimental data.
\end{abstract}

Keywords Ethane $\cdot$ Ethylene $\cdot$ Acetic acid $\cdot$ Partial oxidation $\cdot$ MoVNbPd catalyst

\section{Introduction}

Acetic acid is mainly produced industrially on large scale from methanol carbonylation which accounts for $65 \%$ of world capacity, but gives rise to many problems, such as corrosion and waste disposal. Other processes include acetaldehyde oxidation and ethane partial oxidation. A plant for partial oxidation of ethane to acetic acid is operated by SABIC of Saudi Arabia since 2005. Vinegar which is about 4-6\% diluted form of acetic acid is obtained by fermentation of renewable carbon sources containing ethanol. Acetic acid is primarily used in the production of vinyl acetate monomer (VAM), acetic anhydride and as a solvent in the production of terephthalic acid (TPA).

MoVNb catalysts were shown [1] to be able to effect the partial oxidation of ethane to ethylene and acetic acid. The

Sulaiman I. Al-Mayman

smayman@kacst.edu.sa

1 King Abdul Aziz City for Science and Technology, P.O. Box 6086, Riyadh 11442, Saudi Arabia

2 Department of Chemical Engineering, The British University in Egypt, El-Sherouk City, P.O. Box 43, Cairo 11837, Egypt

3 Department of Chemical Engineering, King Saud University, P.O. Box 800, Riyadh 11421, Saudi Arabia

4 King Saud University, P.O. Box 800, Riyadh 11421, Saudi Arabia addition of Pd makes the catalyst more selective towards acetic acid formation.

The design of industrial reactors for partial oxidation of ethane over MoVNbPd catalyst requires a reliable kinetic model. In this paper we attempt to obtain kinetic expression for ethane partial oxidation based on known mechanisms that are usually used in partial oxidation reactions.

The following three mechanisms are usually used in partial oxidation reactions;

1. Langmuir-Hinshelwood (LH) in which the adsorbed oxygen and adsorbed ethane on the active sites of the catalyst react in the adsorbed states,

2. Eley-Rideal (ER) in which one of the reactants is adsorbed and react in the adsorbed state with the other reactant in the gas phase.

3. Mars-Van Krevelen redox (MvK) in which the oxidized catalyst react with ethane and thus is reduced and is reoxidized with molecular oxygen.

In the pioneering work of Thorsteinson et al. Mo- $\mathrm{V}-\mathrm{Nb}$ catalysts [1], have been reported as active for the partial oxidation of ethane to ethylene and acetic acid using oxygen. In their work the kinetics for $\mathrm{Mo}_{16} \mathrm{~V}_{8} \mathrm{Nb}_{2.29}$ was derived assuming LH mechanism. Two schemes have been suggested to explain the mechanism. In one scheme, ethoxy-hydroxyl species are formed and these decompose to ethylene. In the second scheme a hydroxy-alkoxy is formed and this 
decomposes to ethylene and water. Bare metal sites $\mathrm{M}$ reacts with water to form $\mathrm{MOH}$ which reacts with ethylene to give an ethoxide $\mathrm{MOC}_{2} \mathrm{H}_{5}$. The ethoxide is oxidized to acetic acid.

For acetic acid production, a pressure of about 300 psig gives acetic acid selectivity about $20 \%$, and ethylene selectivity about $70 \%$. In addition, the use of high pressure is advantageous in reducing contact time for a specified ethane conversion and thus reducing the catalytic reactor bed.

To avoid the formation of inflammable mixture, the feed to the reactor contains low percentage of oxygen limiting ethane conversion. This requires the recycle of unreacted ethane.

The kinetics of Thoresteinson et al. has been used for simulation of fixed bed reactor [2], and fluidized bed reactor [3]. To avoid the formation of inflammable mixture, ElSherehy et al. [4] studied the use of distributed oxygen along the reactor bed.

Karim et al. [5] showed that the addition of $\mathrm{Pd}$ to the $\mathrm{MoVNb}$ catalyst greatly increases the selectivity to acetic acid to about $80 \%$ and completely oxidizes $\mathrm{CO}$ to $\mathrm{CO}_{2}$.

Fakeeha et al. [6] obtained the kinetics for MoVPO catalyst. A model based on Eley-Rideal and Mars and Van Krevelen redox mechanisms were found adequate.

The mechanism and kinetics of the reaction with a $\mathrm{Mo}_{1} \mathrm{~V}_{0.25} \mathrm{Nb}_{0.12} \mathrm{Pd}_{0.0005} \mathrm{O}_{x}$ catalyst were studied by Linke et al. $[7,8]$. It has been shown that ethylene inhibits ethane oxidation through depletion of lattice oxygen $\left(\mathrm{O}^{*}\right)$. The consecutive oxidation of ethylene to acetic acid is itself catalyzed by the palladium oxide in a heterogeneous analogue of the Wacker process.

Their kinetic model contains some negative activation energy which is physically wrong. They have indicated that the $\mathrm{C}-\mathrm{H}$ bond activation in ethane by the oxygen-saturated catalyst surfaces is the rate limiting step [7]. Water is also believed to increase acetic acid selectivity by promoting the desorption of acetate species as acetic acid [7].

The kinetics of MoV type catalyst was re-investigated by Rahman et al. [9] but the catalyst composition was not mentioned. Most probably it contains $\mathrm{Nb}$ and Pd. Rahman et al. [9] developed a two-site Eley-Rideal-Redox (ERR) model to predict the partial oxidation of ethane to ethylene and the partial ethane oxidation to acetic acid over the catalyst. To be used in acetic acid plant design, we need to know how much $\mathrm{CO}$ is produced. However, their model assumes that the oxidation of ethylene and acetic acid to $\mathrm{CO}$ is insignificant. Also the oxidation of ethane to $\mathrm{CO}$ and $\mathrm{CO}_{2}$ is negligible.

$\mathrm{Li}$ and Iglesia [10, 11] found that precipitation of Mo, $\mathrm{V}$ and $\mathrm{Nb}$ salts solution in the presence of colloidal $\mathrm{TiO}_{2}$ (titania P25 from Degussa) led to a tenfold increase in ethylene and acetic acid rates (per active oxide) without significant changes in selectivity relative to unsupported samples. The introduction of trace amounts of $\mathrm{Pd}$
(0.0025-0.01 wt\%) as a physical mixture of separate 0.3 (wt\%) $\mathrm{Pd} / \mathrm{SiO}_{2}$ led to the near complete depletion of ethylene and to a significant increase in acetic acid synthesis rate.

A suitable kinetic model for the catalytic oxidation of ethane to acetic acid on MoVNb catalyst must be able to explain the following key observations:

1. Rate of depletion of ethane is first order with respect to ethane as noted by Thorsteinson et al. [1]. Burch and Swarnakar [12] determined the rate of reaction to be $0.8-1.0$ with respect to ethane depending on temperature.

2. Rate of depletion of ethane is a fraction close to zero with respect to oxygen as noted by Thorsteinson et al. [1]. Burch and Swarnakar [12] determined the rate of reaction to be $0.07-0.5$ with respect to oxygen.

3. High pressure favors the formation of acetic acid.

4. Temperature increase makes the reaction more selective to ethylene with respect to acetic acid.

5. The strong acceleration of the rate of the ethylene oxidation to acetic acid by the presence of water (Linke et al. [7, 8]; Rahman et al. [9]). Water, whether formed as a byproduct or added with $\mathrm{C}_{2} \mathrm{H}_{6}-\mathrm{O}_{2}$ reactants, increases acetic acid selectivity by promoting the desorption of adsorbed acetate species as acetic acid. Thus, the promoting effect of water on acetic acid selectivity reflects a specific increase in the rate at which ethane converts to acetic acid via direct pathways. The absence of water led to larger (ethylene/acetic acid) ratios in products and to slightly higher $\mathrm{CO}_{x}$ selectivity.

6. Palladium catalyzes the oxidation of $\mathrm{CO}$ to $\mathrm{CO}_{2}$. Berlowitz et al. [13] have shown that for some range of operating conditions the rate of $\mathrm{CO}$ oxidation is first order in oxygen and negative first order in $\mathrm{CO}$.

The catalyst used in our experiments has the composition $\mathrm{Mo}_{16} \mathrm{~V}_{6.37} \mathrm{Nb}_{2.05} \mathrm{O}_{x} \mathrm{Pd}_{0.0037}^{0} / \mathrm{TiO}_{2}$ (P25). The catalyst loading on Titania is $30 \%$. Pd was added. The method of preparation, catalyst characterization and the effect of operating parameters for the partial oxidation reaction of ethane such as temperature, space time and feed composition are described in references $[15,16]$. The experimental tubular reactor used to carry out the experiments is also described in these two references. This catalyst composition was optimized for maximum acetic acid yield, and thus it is required to develop a kinetic model for its use in the partial oxidation reaction of ethane to acetic acid.

In the next section, the experiments carried out and the results are presented. This is followed by the kinetic model suggested. Parameter estimation results are then presented. The results are then discussed and reaction mechanism is suggested. Finally, conclusions are presented. 


\section{Experimental}

The reaction system set up is described in Ref. [16]. Briefly $0.3 \mathrm{~g}$ of the catalyst diluted with silica particles of the same size is placed in the reactor tube of overall length $150 \mathrm{~mm}$ with inside diameter of made of $6.35 \mathrm{~mm}$ stainless steel and surrounded by brass block. The block is surrounded by mica band heater.

At the beginning of the experiments, we tested the effect of reducing the catalyst particle size on ethane conversion. No noticeable change happened. We concluded that intraparticle mass transfer is negligibly small.

For the present kinetic study sixty-three experiments were carried out for ethane oxidation. Temperatures varied between 225 and $275^{\circ} \mathrm{C}$, pressures from atmospheric to $200 \mathrm{psig}$, total gas inlet flow-rate containing ethane and oxygen from 10 to $40 \mathrm{ml} / \mathrm{min}$, and $\mathrm{O}_{2} \%$ in the feed between 10 and 40. In all experiments, catalyst weight was $0.3 \mathrm{~g}$. Specifically, the following experiments were carried out:

1. At pressure $200 \mathrm{psig}$, and flow-rate $10 \mathrm{ml} / \mathrm{min}$;

(a) One experiment at $225^{\circ} \mathrm{C}$ and $10 \% \mathrm{O}_{2}$

(b) Two experiments at $225,240{ }^{\circ} \mathrm{C}$ and $20 \% \mathrm{O}_{2}$

(c) One experiment at $225^{\circ} \mathrm{C}$ and $40 \% \mathrm{O}_{2}$

2. At pressure $200 \mathrm{psig}$, and flow-rate $20 \mathrm{ml} / \mathrm{min}$;
(a) Two experiments at $225,240{ }^{\circ} \mathrm{C}$ and $10 \% \mathrm{O}_{2}$
(b) Three experiments at $225,240,250{ }^{\circ} \mathrm{C}$ and $20 \%$ $\mathrm{O}_{2}$

(c) Three experiments at $225,250,275^{\circ} \mathrm{C}$ and $40 \%$ $\mathrm{O}_{2}$

3. At pressure $200 \mathrm{psig}$ and flow-rate $40 \mathrm{ml} / \mathrm{min}$

(a) Two experiments at $225,250{ }^{\circ} \mathrm{C}$ and $10 \% \mathrm{O}_{2}$

(b) Four experiments at $225,250{ }^{\circ} \mathrm{C}$ and 20 and $40 \%$ $\mathrm{O}_{2}$

4. At pressure $100 \mathrm{psig}$ and flow-rate $10 \mathrm{ml} / \mathrm{min}$

(a) One experiment at $225{ }^{\circ} \mathrm{C}$ and $10 \% \mathrm{O}_{2}$

(b) Two experiments at $225,250{ }^{\circ} \mathrm{C}$ and $20 \% \mathrm{O}_{2}$

(c) Three experiments at $225,250,275^{\circ} \mathrm{C}$ and $40 \%$ $\mathrm{O}_{2}$

5. At pressure $100 \mathrm{psig}$ and flow-rate $20 \mathrm{ml} / \mathrm{min}$,

(a) One experiment at $225{ }^{\circ} \mathrm{C}$ and $10 \% \mathrm{O}_{2}$

(b) Two experiments at $225,250{ }^{\circ} \mathrm{C}$ and $40 \% \mathrm{O}_{2}$.

6. At pressure $100 \mathrm{psig}$ and flow-rate $40 \mathrm{ml} / \mathrm{min}$, nine experiments at $225,250,275{ }^{\circ} \mathrm{C}$ and 10,20 and $40 \% \mathrm{O}_{2}$.

7. At pressure $0 \mathrm{psig}$, twenty-seven experiments at 225 , $250,275^{\circ} \mathrm{C}$ and 10,20 and $40 \% \mathrm{O}_{2}$, flow-rates of 10,20 and $40 \mathrm{ml} / \mathrm{min}$.

The results are shown in Table 1.

Some observations can be made from testing results:

1. Acetic acid is not formed at atmospheric pressure.
2. Ethylene is the primary product at low temperature and low pressure.

3. Ethylene selectivity decreases with the increase of temperature.

4. Acetic acid is the primary product at high pressure and low temperature.

5. In all experiments the selectivity of $\mathrm{CO}$ was very low.

6. The selectivity of $\mathrm{CO}_{2}$ increases with the increase of temperature and the increase in $\mathrm{O}_{2} \%$ in the feed.

7. The pressure range for the experiments is very wide with high selectivity to ethylene and $\mathrm{CO}_{2}$ at low pressure and high selectivity to acetic acid at high pressure. It would be a challenge to find a model that is suitable for wide variation in the pressure.

\section{Kinetic modeling of partial oxidation of ethane}

Here we attempt to obtain kinetic expression based on known mechanisms that are usually used in partial oxidation reactions. These are Langmuir-Hinshelwood (LH) kinetics assuming reaction taking place between adsorbed species, Eley-Rideal kinetics assuming reaction taking place between adsorbed species and gaseous reactant, and Mars-Van Krevelen redox mechanism in which the oxidized catalyst react with ethane and thus is reduced and is reoxidized with molecular oxygen.

For the reaction

$\mathrm{A}+\frac{1}{2} \mathrm{O}_{2} \rightarrow \mathrm{B}+\mathrm{H}_{2} \mathrm{O}$,

where A could be a hydrocarbon and B is the corresponding dehydrogenated hydrocarbon.

Langmuir-Hinshelwood kinetics takes the form

Rate of oxidation reaction $=\frac{k P_{\mathrm{A}}^{\mathrm{m} 1} P_{\mathrm{O}_{2}}^{\mathrm{m} 2}}{\left[1+K_{1} P_{\mathrm{O}_{2}}+K_{2} P_{\mathrm{A}}+K_{3} P_{\mathrm{B}}+K_{4} P_{w}\right]^{\mathrm{m} 3}}$.

While the redox kinetics take the form

Rate of oxidation reaction $=\frac{k P_{\mathrm{A}} P_{\mathrm{O}_{2}}}{P_{\mathrm{O}_{2}}+K P_{\mathrm{A}}}$.

The reaction network is assumed in its most general form of Fig. 1 ( $r_{\mathrm{i}}$ 's denote reaction rates of different species).

This assumes that acetic acid can be obtained from ethane and ethylene and that all reactants and products are oxidized to $\mathrm{CO}$ and $\mathrm{CO}_{2}$ and $\mathrm{CO}$ is converted to $\mathrm{CO}_{2}$.

We assume the conversion of ethane is $X_{1}$, the conversion to $\mathrm{CO}$ is $\mathrm{X}_{2}, \mathrm{CO}_{2}$ is $\mathrm{X}_{3}$, and $\mathrm{CH}_{3} \mathrm{COOH}$ is $X_{4}$. In 
Table 1 Results of kinetic study

\begin{tabular}{|c|c|c|c|c|c|c|c|c|c|c|c|}
\hline \multirow[t]{2}{*}{$\begin{array}{l}\text { Pressure } \\
\text { psig }\end{array}$} & \multirow[t]{2}{*}{$\begin{array}{l}\text { Flow } \\
\mathrm{ccm} / \mathrm{min}\end{array}$} & \multirow[t]{2}{*}{$\begin{array}{l}\mathrm{O}_{2} \\
\text { In feed } \%\end{array}$} & \multirow[t]{2}{*}{ Temp. ${ }^{\circ} \mathrm{C}$} & \multirow[t]{2}{*}{$\mathrm{O}_{2}$ conv. $\%$} & \multirow[t]{2}{*}{$\mathrm{C}_{2} \mathrm{H}_{6}$ conv. $\%$} & \multicolumn{4}{|c|}{ Selectivity (\%) } & \multicolumn{2}{|c|}{$\begin{array}{l}\text { Space time yield } \\
\mathrm{gm} / \mathrm{kg} \mathrm{h}\end{array}$} \\
\hline & & & & & & Ethylene & Acetic acid & $\mathrm{CO}$ & $\mathrm{CO}_{2}$ & Acetic acid & Ethylene \\
\hline 200 & 10 & 10 & 225 & 99.49 & 4.04 & 2.06 & 82.79 & 0.00 & 15.15 & 161.26 & 1.87 \\
\hline 200 & 10 & 20 & 225 & 74.98 & 6.37 & 1.08 & 83.81 & 0.31 & 14.8 & 228.80 & 1.38 \\
\hline 200 & 10 & 20 & 240 & 99.32 & 9.25 & 0.37 & 81.79 & 0.09 & 17.74 & 324.23 & 0.69 \\
\hline 200 & 10 & 40 & 225 & 42.68 & 9.52 & 0.83 & 77.01 & 0.28 & 21.88 & 235.64 & 1.19 \\
\hline 200 & 20 & 10 & 225 & 66.09 & 3.26 & 6.71 & 77.84 & 0.67 & 14.78 & 244.69 & 9.84 \\
\hline 200 & 20 & 10 & 240 & 99.42 & 4.89 & 4.08 & 79.47 & 0.4 & 16.05 & 374.72 & 8.98 \\
\hline 200 & 20 & 20 & 225 & 42.09 & 4.80 & 2.62 & 81.76 & 0.47 & 15.15 & 336.38 & 5.03 \\
\hline 200 & 20 & 20 & 240 & 72.71 & 7.31 & 1.43 & 79.75 & 0.32 & 18.50 & 499.68 & 4.18 \\
\hline 200 & 20 & 20 & 250 & 97.16 & 9.56 & 0.82 & 78.82 & 0.22 & 20.15 & 645.86 & 3.14 \\
\hline 200 & 20 & 40 & 225 & 24.31 & 6.44 & 2.59 & 82.00 & 0.56 & 14.85 & 339.47 & 5.00 \\
\hline 200 & 20 & 40 & 250 & 62.54 & 15.18 & 0.73 & 71.2 & 0.23 & 27.84 & 694.79 & 3.32 \\
\hline 200 & 20 & 40 & 275 & 99.94 & 21.96 & 0.15 & 64.64 & 0.16 & 35.06 & 912.51 & 0.99 \\
\hline 200 & 40 & 10 & 225 & 30.68 & 1.78 & 12.76 & 71.61 & 1.32 & 14.32 & 245.82 & 20.44 \\
\hline 200 & 40 & 10 & 250 & 79.12 & 3.50 & 4.99 & 76.65 & 0.52 & 17.84 & 517.37 & 15.72 \\
\hline 200 & 40 & 20 & 225 & 17.12 & 2.21 & 10.29 & 76.17 & 1.36 & 12.18 & 288.57 & 18.19 \\
\hline 200 & 40 & 20 & 250 & 49.97 & 6.12 & 2.67 & 78.79 & 0.54 & 18.00 & 826.60 & 13.07 \\
\hline 200 & 40 & 40 & 225 & 12.21 & 3.01 & 6.99 & 74.77 & 1.26 & 16.99 & 289.35 & 12.62 \\
\hline 200 & 40 & 40 & 250 & 27.21 & 7.93 & 2.44 & 74.1 & 0.59 & 22.88 & 755.48 & 11.61 \\
\hline 100 & 10 & 10 & 225 & 75.53 & 2.88 & 2.30 & 82.83 & 0.15 & 14.718 & 115.01 & 1.49 \\
\hline 100 & 10 & 20 & 225 & 43.54 & 4.53 & 1.95 & 81.9 & 0.17 & 15.98 & 159.00 & 1.77 \\
\hline 100 & 10 & 20 & 250 & 99.04 & 11.08 & 0.76 & 82.45 & 0.17 & 16.62 & 391.50 & 1.68 \\
\hline 100 & 10 & 40 & 225 & 21.34 & 6.15 & 1.67 & 77.46 & 0.15 & 20.72 & 153.12 & 1.54 \\
\hline 100 & 10 & 40 & 250 & 61.19 & 14.95 & 0.72 & 73.97 & 0.17 & 25.14 & 355.44 & 1.62 \\
\hline 100 & 10 & 40 & 275 & 99.96 & 23.14 & 0.24 & 68.41 & 0.11 & 31.24 & 508.81 & 0.83 \\
\hline 100 & 20 & 10 & 225 & 21.82 & 2.14 & 11.89 & 75.19 & 2.06 & 10.87 & 155.16 & 11.45 \\
\hline 100 & 20 & 40 & 225 & 11.03 & 3.57 & 6.92 & 74.61 & 0.89 & 17.57 & 171.23 & 7.41 \\
\hline 100 & 20 & 40 & 250 & 31.62 & 8.38 & 2.32 & 71.00 & 0.50 & 26.18 & 382.48 & 5.83 \\
\hline 100 & 40 & 10 & 225 & 12.16 & 0.50 & 84.34 & 0.00 & 0.97 & 14.69 & 0.00 & 37.95 \\
\hline 100 & 40 & 10 & 250 & 42.77 & 1.20 & 27.22 & 45.30 & 2.27 & 25.22 & 104.83 & 29.40 \\
\hline 100 & 40 & 10 & 275 & 96.39 & 4.02 & 16.47 & 57.54 & 1.13 & 24.86 & 446.09 & 59.59 \\
\hline 100 & 40 & 20 & 225 & 7.26 & 1.63 & 27.52 & 61.33 & 2.05 & 9.10 & 171.37 & 35.89 \\
\hline 100 & 40 & 20 & 250 & 25.57 & 2.61 & 16.14 & 59.04 & 2.31 & 22.51 & 264.16 & 33.70 \\
\hline 100 & 40 & 20 & 275 & 76.45 & 8.18 & 3.39 & 70.68 & 0.6 & 25.33 & 991.11 & 22.18 \\
\hline 100 & 40 & 40 & 225 & 5.82 & 1.20 & 31.99 & 45.25 & 3.59 & 19.17 & 69.81 & 23.03 \\
\hline 100 & 40 & 40 & 250 & 14.77 & 4.80 & 6.96 & 72.73 & 1.53 & 18.78 & 448.84 & 20.05 \\
\hline 100 & 40 & 40 & 275 & 43.92 & 11.96 & 1.77 & 67.05 & 0.70 & 30.48 & 1031.01 & 12.70 \\
\hline 0 & 10 & 10 & 225 & 15.25 & 0.98 & 100.00 & 0.00 & 0.00 & 0.00 & 0.00 & 22.05 \\
\hline 0 & 10 & 10 & 250 & 41.76 & 1.98 & 86.15 & 0.00 & 2.54 & 11.31 & 0.00 & 38.38 \\
\hline 0 & 10 & 10 & 275 & 90.01 & 3.56 & 58.51 & 0.00 & 6.89 & 34.60 & 0.00 & 46.87 \\
\hline 0 & 10 & 20 & 225 & 8.35 & 1.01 & 100.00 & 0.00 & 0.00 & 0.00 & 0.00 & 20.20 \\
\hline 0 & 10 & 20 & 250 & 21.85 & 2.02 & 80.07 & 0.00 & 1.34 & 18.59 & 0.00 & 32.35 \\
\hline 0 & 10 & 20 & 275 & 58.42 & 3.75 & 49.13 & 0.00 & 7.11 & 43.76 & 0.00 & 36.85 \\
\hline 0 & 10 & 40 & 225 & 3.12 & 1.30 & 91.42 & 0.00 & 0.00 & 8.58 & 0.00 & 17.83 \\
\hline 0 & 10 & 40 & 250 & 11.75 & 2.50 & 74.55 & 0.00 & 2.66 & 22.78 & 0.00 & 27.96 \\
\hline 0 & 10 & 40 & 275 & 35.46 & 4.80 & 37.33 & 0.00 & 9.07 & 53.60 & 0.00 & 26.88 \\
\hline 0 & 20 & 10 & 225 & 6.83 & 0.52 & 100 & 0.00 & 0.00 & 0.00 & 0.00 & 23.40 \\
\hline 0 & 20 & 10 & 250 & 16.61 & 1.13 & 90.22 & 0.00 & 0.00 & 9.79 & 0.00 & 45.88 \\
\hline
\end{tabular}


Table 1 (continued)

\begin{tabular}{|c|c|c|c|c|c|c|c|c|c|c|c|}
\hline \multirow[t]{2}{*}{$\begin{array}{l}\text { Pressure } \\
\text { psig }\end{array}$} & \multirow[t]{2}{*}{$\begin{array}{l}\text { Flow } \\
\mathrm{ccm} / \mathrm{min}\end{array}$} & \multirow[t]{2}{*}{$\begin{array}{l}\mathrm{O}_{2} \\
\text { In feed } \%\end{array}$} & \multirow[t]{2}{*}{ Temp. ${ }^{\circ} \mathrm{C}$} & \multirow[t]{2}{*}{$\mathrm{O}_{2}$ conv. $\%$} & \multirow[t]{2}{*}{$\mathrm{C}_{2} \mathrm{H}_{6}$ conv. $\%$} & \multicolumn{4}{|c|}{ Selectivity (\%) } & \multicolumn{2}{|c|}{$\begin{array}{l}\text { Space time yield } \\
\mathrm{gm} / \mathrm{kg} \mathrm{h}\end{array}$} \\
\hline & & & & & & Ethylene & Acetic acid & $\mathrm{CO}$ & $\mathrm{CO}_{2}$ & Acetic acid & Ethylene \\
\hline 0 & 20 & 10 & 275 & 48.95 & 2.11 & 74.38 & 0.00 & 3.29 & 22.33 & 0.00 & 70.62 \\
\hline 0 & 20 & 20 & 225 & 3.82 & 0.57 & 100 & 0.00 & 0.00 & 0.00 & 0.00 & 22.80 \\
\hline 0 & 20 & 20 & 250 & 7.20 & 1.25 & 91.10 & 0.00 & 0.00 & 8.90 & 0.00 & 45.55 \\
\hline 0 & 20 & 20 & 275 & 29.73 & 2.65 & 63.67 & 0.00 & 9.03 & 27.31 & 0.00 & 67.49 \\
\hline 0 & 20 & 40 & 225 & 1.88 & 0.73 & 100 & 0.00 & 0.00 & 0.00 & 0.00 & 21.90 \\
\hline 0 & 20 & 40 & 250 & 4.59 & 1.49 & 85.21 & 0.00 & 0.00 & 14.79 & 0.00 & 38.09 \\
\hline 0 & 20 & 40 & 275 & 15.84 & 3.27 & 55.29 & 0.00 & 10.92 & 33.79 & 0.00 & 54.24 \\
\hline 0 & 40 & 10 & 225 & 4.96 & 0.38 & 100 & 0.00 & 0.00 & 0.00 & 0.00 & 34.20 \\
\hline 0 & 40 & 10 & 250 & 11.12 & 0.75 & 100 & 0.00 & 0.00 & 0.00 & 0.00 & 67.50 \\
\hline 0 & 40 & 10 & 275 & 29.77 & 1.51 & 85.81 & 0.00 & 2.77 & 11.42 & 0.00 & 116.62 \\
\hline 0 & 40 & 20 & 225 & 3.24 & 0.43 & 100 & 0.00 & 0.00 & 0.00 & 0.00 & 34.40 \\
\hline 0 & 40 & 20 & 250 & 6.66 & 0.82 & 100 & 0.00 & 0.00 & 0.00 & 0.00 & 65.60 \\
\hline 0 & 40 & 20 & 275 & 17.43 & 1.76 & 80.34 & 0.00 & 3.01 & 16.66 & 0.00 & 113.12 \\
\hline 0 & 40 & 40 & 225 & 2.86 & 0.49 & 100 & 0.00 & 0.00 & 0.00 & 0.00 & 29.40 \\
\hline 0 & 40 & 40 & 250 & 3.48 & 1.12 & 89.98 & 0.00 & 0.00 & 10.02 & 0.00 & 60.47 \\
\hline 0 & 40 & 40 & 275 & 8.14 & 2.17 & 70.64 & 0.00 & 2.66 & 26.70 & 0.00 & 91.97 \\
\hline
\end{tabular}

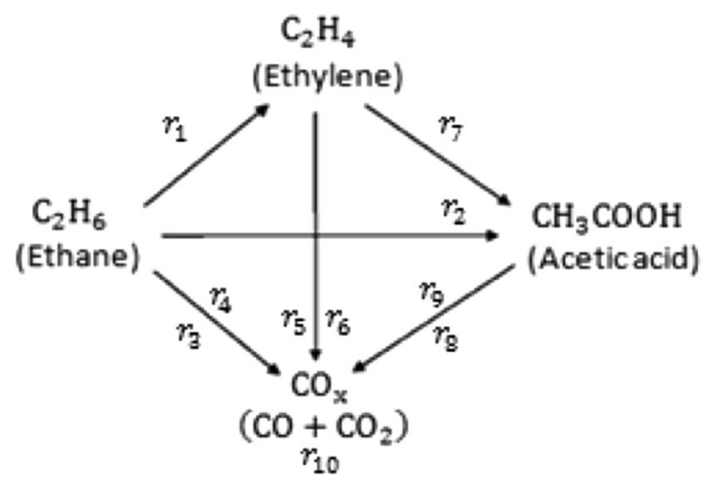

Fig. 1 Proposed scheme for ethane partial oxidation

addition, we assume that the reactor operates in the integral mode. Thus, we have

$\tau=\frac{W}{F_{\mathrm{C}_{2} \mathrm{H}_{6}}}$

$\frac{\mathrm{d} X_{1}}{\mathrm{~d} \tau}=r_{\mathrm{C}_{2} \mathrm{H}_{6}}$

$\frac{\mathrm{d} X_{2}}{\mathrm{~d} \tau}=r_{\mathrm{CO}}$

$\frac{\mathrm{d} X_{3}}{\mathrm{~d} \tau}=r_{\mathrm{CO}_{2}}$ $\frac{\mathrm{d} X_{4}}{\mathrm{~d} \tau}=r_{\mathrm{CH}_{3} \mathrm{COOH}}$

With the initial conditions at

$\tau=\frac{W}{F_{\mathrm{C}_{2} \mathrm{H}_{6}}}=0, X_{1}=X_{2}=X_{3}=X_{4}=0$,

where $W=$ catalyst weight $F_{\mathrm{C} 2 \mathrm{H} 6}=$ volumetric flow-rate of ethane in the feed.

The rate of depletion of ethane $\left(r_{\mathrm{C}_{2} \mathrm{H}_{6}}\right)$ is given by

$r_{\mathrm{C}_{2} \mathrm{H}_{6}}=r_{1}+r_{2}+\frac{1}{2} r_{3}+\frac{1}{2} r_{4}$,

where $r_{1}$ is the rate of oxidation of ethane to ethylene; $r_{2}$ is the rate of oxidation of ethane to acetic acid; $r_{3}$ is the rate of formation of $\mathrm{CO}$ by ethane oxidation and $r_{4}$ is the rate of formation of $\mathrm{CO}_{2}$ by ethane oxidation.

The rate of formation of $\mathrm{CO}\left(r_{\mathrm{CO}}\right)$ is given by

$r_{\mathrm{CO}}=r_{3}+r_{5}+r_{8}-r_{10}$,

where $r_{5}$ is the rate of formation of $\mathrm{CO}$ from ethylene oxidation, $r_{8}$ is the rate of formation of $\mathrm{CO}$ from acetic acid oxidation, and $r_{10}$ is the rate of oxidation of $\mathrm{CO}$ to $\mathrm{CO}_{2}$.

The rate of formation of $\mathrm{CO}_{2}\left(r_{\mathrm{CO}_{2}}\right)$ is given by

$r_{\mathrm{CO}_{2}}=r_{4}+r_{6}+r_{9}+r_{10}$,

where $r_{6}$ is the rate of formation of $\mathrm{CO}_{2}$ from ethylene oxidation, and $r_{9}$ is the rate of formation of $\mathrm{CO}_{2}$ from acetic acid oxidation, and $r_{10}$ is the rate of oxidation of $\mathrm{CO}$ to $\mathrm{CO}_{2}$.

The rate of formation of $\mathrm{CH}_{3} \mathrm{COOH}\left(r_{\mathrm{CH} 3 \mathrm{OOH}}\right)$ is given by 
$r_{\mathrm{CH}_{3} \mathrm{OOH}}=r_{2}+r_{7}-\frac{1}{2} r_{8}-\frac{1}{2} r_{9}$,

where $r_{7}$ is the rate of formation of acetic acid from ethylene.

The expressions for $r_{1}-r_{10}$ are given by

$r_{1}=\frac{k_{1} \times P_{\mathrm{C}_{2} \mathrm{H}_{6}} \times P_{\mathrm{O}_{2}}}{P_{\mathrm{O}_{2}}+K_{1} \times P_{\mathrm{C}_{2} \mathrm{H}_{6}}}$

$r_{2}=\frac{k_{2} \times P_{\mathrm{C}_{2} \mathrm{H}_{6}}^{2} \times P_{\mathrm{O}_{2}}^{2}}{\left(P_{\mathrm{O}_{2}}+K_{1} \times P_{\mathrm{C}_{2} \mathrm{H}_{6}}\right)^{2}}$

$r_{3}=\frac{k_{3} \times P_{\mathrm{C}_{2} \mathrm{H}_{6}} \times P_{\mathrm{O}_{2}}}{P_{\mathrm{O}_{2}}+K_{1} \times P_{\mathrm{C}_{2} \mathrm{H}_{6}}}$

$r_{4}=\frac{k_{4} \times P_{\mathrm{C}_{2} \mathrm{H}_{6}} \times P_{\mathrm{O}_{2}}}{P_{\mathrm{O}_{2}}+K_{1} \times P_{\mathrm{C}_{2} \mathrm{H}_{6}}}$

$r_{5}=\frac{k_{5} \times P_{\mathrm{C}_{2} \mathrm{H}_{4}} \times P_{\mathrm{O}_{2}}}{P_{\mathrm{O}_{2}}+K_{2} \times P_{\mathrm{C}_{2} \mathrm{H}_{4}}}$

$r_{6}=\frac{k_{6} \times P_{\mathrm{C}_{2} \mathrm{H}_{4}} \times P_{\mathrm{O}_{2}}}{P_{\mathrm{O}_{2}}+K_{2} \times P_{\mathrm{C}_{2} \mathrm{H}_{4}}}$

$r_{7}=\frac{k_{7} \times P_{\mathrm{C}_{2} \mathrm{H}_{4}}^{2} \times P_{\mathrm{O}_{2}} \times P_{\mathrm{H}_{2} \mathrm{O}}}{P_{\mathrm{O}_{2}}+K_{3} \times P_{\mathrm{C}_{2} \mathrm{H}_{4}}}$

$r_{8}=\frac{k_{8} \times P_{\mathrm{CH}_{3} \mathrm{COOH}} \times P_{O_{2}}}{P_{\mathrm{O}_{2}}+K_{3} \times P_{\mathrm{C}_{2} \mathrm{H}_{4}}}$

$r_{9}=\frac{k_{9} \times P_{\mathrm{CH}_{3} \mathrm{COOH}} \times P_{\mathrm{O}_{2}}}{P_{\mathrm{O}_{2}}+K_{3} \times P_{\mathrm{C}_{2} \mathrm{H}_{4}}}$

$r_{10}=\frac{k_{10} \times P_{\mathrm{CO}} \times P_{\mathrm{O}_{2}}}{\left(P_{\mathrm{CO}}+K_{4} P_{\mathrm{O}_{2}}\right)^{2}}$,

with the $k$ 's are defined as

$k_{i}=k_{i, o} \times \exp \frac{-E_{i}}{R}\left(\frac{1}{T}-\frac{1}{548.15}\right)$,

where: all pressures are in atmosphere, the rates are in $\mathrm{Ncm}^{3}$ / min $g, k_{i}$ 's units can be deduced. $K_{i}$ 's are dimensionless, $E_{i}$ is activation energy in cal $/ \mathrm{mol}, T$ is in $\mathrm{K}$ and $R=1.98 \mathrm{cal} /$ mol K. The dependence of the adsorption constants (K's) on temperature was insignificant.

The calculated conversions are obtained by integrating equations subject to the initial condition. The pressures of the different components in terms of conversions are obtained as follows.

Let $X_{1}$ be the conversion of ethane, $X_{2}$ number of moles of $\mathrm{CO}$ produced per mole of ethane, $X_{3}$ number of moles of $\mathrm{CO}_{2}$ produced per mole of ethane $X_{4}$ number of mole of $\mathrm{CH}_{3} \mathrm{COOH}$ produced per mole of ethane.,

$Y_{1}$ moles of $\mathrm{O}_{2}$ per mole of ethane and $n t$ total number of moles of products per mole of ethane. Thus

$$
\begin{array}{cc}
\mathrm{C}_{2} \mathrm{H}_{6}+\frac{1}{2} \mathrm{O}_{2} \rightarrow & \mathrm{C}_{2} \mathrm{H}_{4}+\mathrm{H}_{2} \mathrm{O} \\
-X_{1}-\frac{1}{2} X_{1} & X_{1} \quad X_{1} \\
& \\
\mathrm{C}_{2} \mathrm{H}_{4}+\mathrm{O}_{2} \rightarrow & \mathrm{CH}_{3} \mathrm{COOH} \\
-X_{4}-X_{4} & X_{4} \\
\mathrm{C}_{2} \mathrm{H}_{4}+3 \mathrm{O}_{2} \rightarrow & 2 \mathrm{CO}_{2}+2 \mathrm{H}_{2} \mathrm{O} \\
-\frac{1}{2} X_{3}-\frac{3}{2} X_{3} & X_{3} X_{3}
\end{array}
$$

Moles of ethane $=1-X_{1}$

Moles of oxygen $=Y_{1}-\frac{1}{2} X_{1}-X_{2}-\frac{3}{2} X_{3}-X_{4}$

Moles of ethylene $=X_{1}-\frac{1}{2} X_{2}-\frac{1}{2} X_{3}-X_{4}$

Moles of $\mathrm{CH}_{3} \mathrm{COOH}=X_{4}$

Moles of $\mathrm{CO}=X_{2}$

Moles of $\mathrm{CO}_{2}=X_{3}$

Moles of $\mathrm{H}_{2} \mathrm{O}=X_{1}+X_{2}+X_{3}$

Total moles $(n t)=1+Y_{1}+\frac{1}{2} X_{1}+\frac{1}{2} X_{2}-X_{4}$.

Thus, the partial pressures of the different compounds are as follows:

$P_{\mathrm{C}_{2} \mathrm{H}_{6}}=\frac{\left(1-X_{1}\right)}{n t} P_{t}$

$P_{\mathrm{O}_{2}}=\frac{\left(Y_{1}-\frac{1}{2} X_{1}-X_{2}-\frac{3}{2} X_{3}-X_{4}\right)}{n t} P_{t}$

$P_{\mathrm{C}_{2} \mathrm{H}_{4}}=\frac{\left(X_{1}-\frac{1}{2} X_{2}-\frac{1}{2} X_{3}-X_{4}\right)}{n t} P_{t}$ 
$P_{\mathrm{CH}_{3} \mathrm{COOH}}=\frac{X_{4}}{n t} P_{t}$

$P_{\mathrm{CO}}=\frac{X_{2}}{n t} P_{t}$

$P_{\mathrm{CO}_{2}}=\frac{X_{3}}{n t} P_{t}$

$P_{\mathrm{H}_{2} \mathrm{O}}=\frac{\left(X_{1}+X_{2}+X_{3}\right)}{n t} P_{t}$,

where $P_{t}=$ total pressure

Parameter estimation was done by the minimization of weighted residual squares of the conversions. The resulting non-linear equations are solved by Marquardt method. The method used is described in details by Hosten et al. [14].

The computer package for carrying out estimation calculations provides statistical data. They are $F$ value for judging goodness of fit. $t$ values for significance of parameters and $95 \%$ confidence regions of the parameter estimation and some others.

If the $F$ value is small, the fit of the model is poor. At fixed number of parameters and experiments the higher is the $F$ value the better is the fit. If a parameter is found to have very small $t$ value, it means that it does not have a significant effect in determining the reaction rates and should be eliminated from the rate equations.

\section{Parameter estimation results}

Preliminary screening led us to conclude that the rate of oxidation of ethane to acetic acid and $\mathrm{CO}$ is negligibly small, i.e., $r_{2}=0$ and $r_{3}=0$. In addition, the rate of oxidation of ethylene to $\mathrm{CO}$ and $\mathrm{CO}_{2}$ is negligibly small, i.e., $r_{5}=0$ and $r_{6}=0$. We obtain the following parameter estimates (Table 2).
Table 2 Parameter estimates; $F=342.6$, residual sum of squares $=0.024$

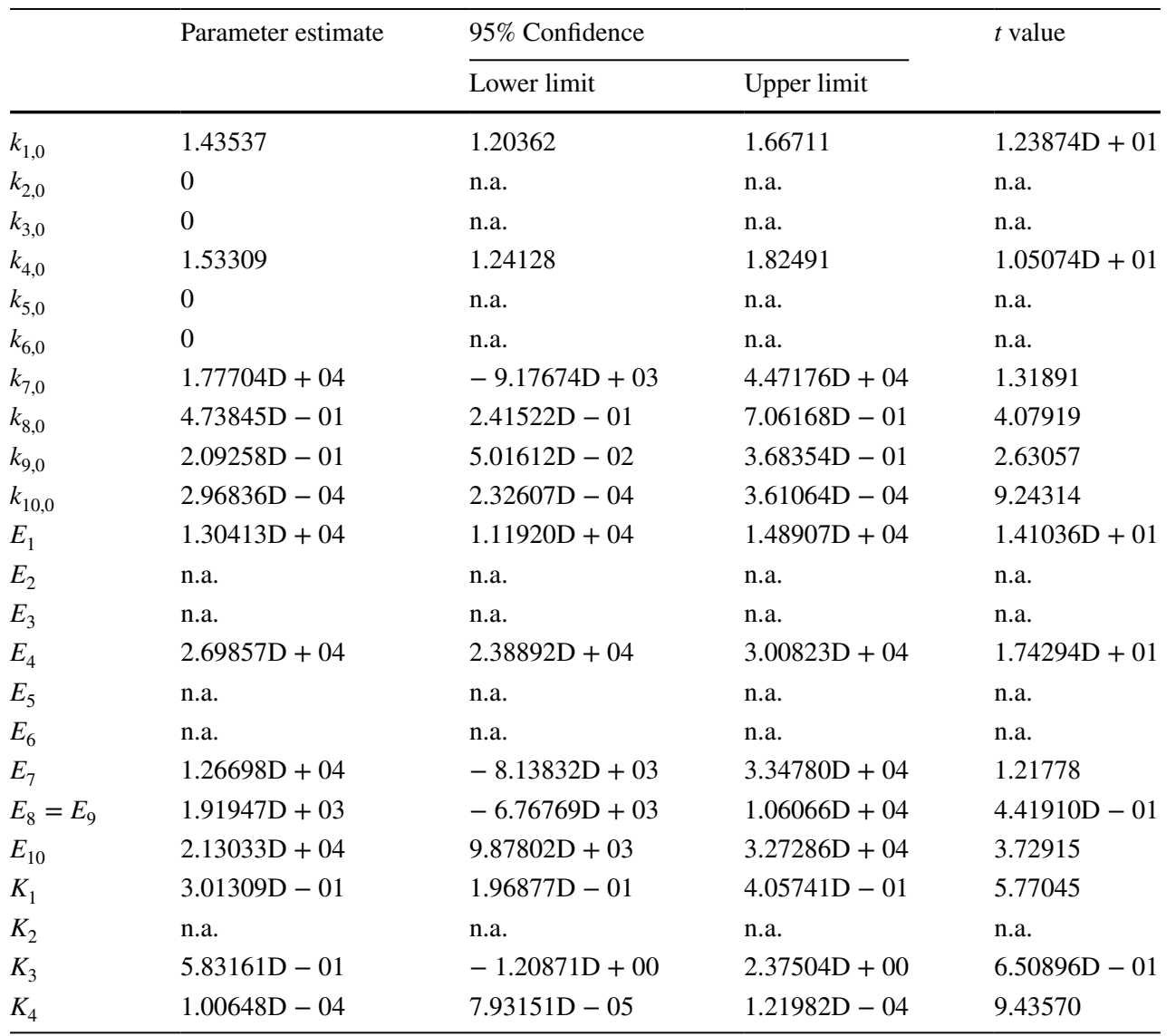

The values of the rate of reactions considered in this work are based on the units of normal $\mathrm{cm}^{3} / \mathrm{min} \mathrm{g}$ They must be multiplied by 0.00268 to transform them to the more usual units of $\mathrm{mol} / \mathrm{h} \mathrm{g}$ catalyst n.a. not applicable 


\section{Discussion}

We were not able to fit our experimental results with the model of Rahman et al. [9]. Thus, the model needs modifications for our case since we are using a different catalyst. Parameter estimation results indicate that the main reactions taking place are the oxidation of ethane to ethylene and $\mathrm{CO}_{2}$ and the oxidation of ethylene to acetic acid. Some of acetic acid is also oxidized to $\mathrm{CO}$ and $\mathrm{CO}_{2}$. $\mathrm{CO}$ is oxidized to $\mathrm{CO}_{2}$. The final reaction network takes the form of Fig. 2.

The results indicate that oxidation reactions take place on different sites. Ethane oxidation takes place on one site. Ethylene oxidation in presence of water to acetic acid takes place on another site. $\mathrm{CO}$ is oxidized to $\mathrm{CO}_{2}$ on a third site.

The estimation results indicate that a redox mechanism is more suitable to explain the reactions taking place for the oxidation of ethane to ethylene. Equation (14) for ethane oxidation to ethylene takes the familiar form of redox kinetics. The parameters associated with the oxidation of ethane to ethylene are determined with large $t$ values giving high confidence in their values. For the oxidation of ethane to ethylene, our results agree with Linke et al. [7]. For the oxidation of ethylene to acetic acid our results also agree with that of Linke et al. [7] that acetic acid is related to the formation of a hydroxyl group from water on the active site. There are some controversy of whether ethane or ethylene oxidizes to $\mathrm{CO}$ and $\mathrm{CO}_{2}$. Burch and Swanakar [12] suggested that $\mathrm{CO}$ and $\mathrm{CO}_{2}$.are formed to a large extent from ethane. On the contrary Thorsteinson et al. [1] suggested that ethylene oxidizes into $\mathrm{CO}$ and $\mathrm{CO}_{2}$. Our results suggest that $\mathrm{CO}_{2}$ is mainly obtained from ethane and acetic acid whereas $\mathrm{CO}$ is obtained from acetic acid. This $\mathrm{CO}$ is then oxidized to $\mathrm{CO}_{2}$ on sites containing Pd. For reactions involving ethylene, acetic acid and $\mathrm{CO}$ a LH kinetic model is suggested.

For the oxidation of ethylene to acetic acid, Rahman et al. [9] suggested two routes one involves water and the second does not involve water. We found that acetic acid formation

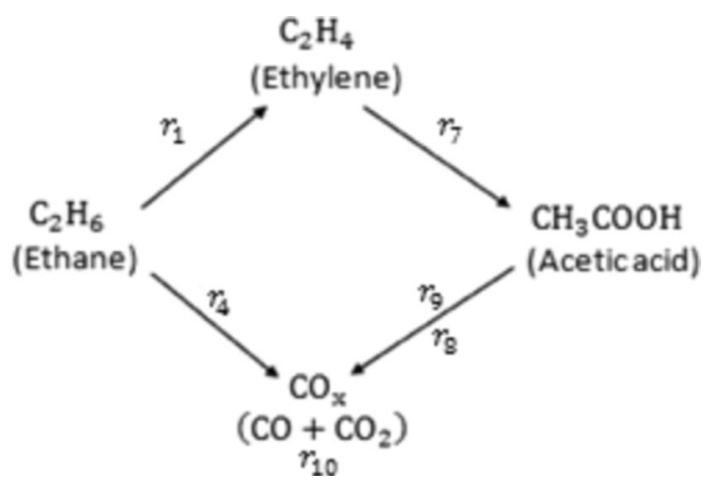

Fig. 2 Modified scheme for ethane partial oxidation from the second route is not significant. The first route involving water needs modification. Let $\mathrm{Y}$ be a catalytic center for ethylene oxidation to acetic acid. Consider the following scheme;

$2 \mathrm{Y}+2 \mathrm{O}_{2} \rightleftarrows 2 \mathrm{YO}_{2}$

$\mathrm{C}_{2} \mathrm{H}_{4}+\mathrm{Y} \rightleftarrows \mathrm{C}_{2} \mathrm{H}_{4} \mathrm{Y}$

$2 \mathrm{C}_{2} \mathrm{H}_{4}+\mathrm{YO}_{2} \rightleftarrows\left(\mathrm{CH}_{3} \mathrm{CH}\right)_{2} \mathrm{OYO}$

$\left(\mathrm{CH}_{3} \mathrm{CH}\right)_{2} \mathrm{OYO}+\mathrm{H}_{2} \mathrm{O} \rightleftarrows\left(\mathrm{CH}_{3} \mathrm{CH}\right)_{2} \mathrm{OY}(\mathrm{OH})_{2}$

$\left(\mathrm{CH}_{3} \mathrm{CH}\right)_{2} \mathrm{OY}(\mathrm{OH})_{2} \rightarrow\left(\mathrm{CH}_{3} \mathrm{CHO}\right)_{2} \mathrm{Y}+\mathrm{H}_{2} \mathrm{O}(\mathrm{RDS})$

$\left(\mathrm{CH}_{3} \mathrm{CHO}\right)_{2} \mathrm{Y}+\mathrm{YO}_{2} \rightarrow 2 \mathrm{CH}_{3} \mathrm{COOH}+2 \mathrm{Y}$ (fast).

This leads to the following rate equation

$r_{7}=k \frac{k_{7} \times P_{\mathrm{C}_{2} \mathrm{H}_{4}}^{2} \times P_{\mathrm{O}_{2}} \times P_{\mathrm{H}_{2} \mathrm{O}}}{1+k\left(P_{\mathrm{O}_{2}}+K_{3} \times P_{\mathrm{C}_{2} \mathrm{H}_{4}}+\text { negligibe adsorption terms } \ldots . .\right)}$.

For large $k$ this equation simplifies to Eq. (20).

For the oxidation of acetic acid to $\mathrm{CO}$ and $\mathrm{CO}_{2}$, we suggest the following scheme

$\frac{3}{2} \mathrm{Y}+\frac{3}{2} \mathrm{O}_{2} \rightleftarrows \frac{3}{2} \mathrm{YO}_{2}$

$\frac{1}{2} \mathrm{Y}+\frac{1}{4} \mathrm{O}_{2} \rightleftarrows \frac{1}{2} \mathrm{YO}$

$\mathrm{CH}_{3} \mathrm{COOH}+\mathrm{YO}_{2} \rightarrow \mathrm{CH}_{3} \mathrm{COOHYO}_{2}(\mathrm{RDS})$

$\frac{1}{2} \mathrm{CH}_{3} \mathrm{COOHYO}_{2}+\frac{1}{2} \mathrm{YO}_{2} \rightarrow \mathrm{CO}_{2}+\mathrm{H}_{2} \mathrm{O}+\mathrm{Y}$ (fast)

$\frac{1}{2} \mathrm{CH}_{3} \mathrm{COOHYO}_{2}+\frac{1}{2} \mathrm{YO} \rightarrow \mathrm{CO}+\mathrm{H}_{2} \mathrm{O}+\mathrm{Y}$ (fast),

which leads to the following rate equations

$r_{8}=k \frac{k_{8} \times P_{\mathrm{CH}_{3} \mathrm{COOH}} \times P_{\mathrm{O}_{2}}}{1+k\left(P_{\mathrm{O}_{2}}+K_{3} \times P_{\mathrm{C}_{2} \mathrm{H}_{4}}+\text { negligibe adsorption terms } \ldots . .\right)}$,

$r_{9}=k \frac{k_{9} \times P_{\mathrm{CH}_{3} \mathrm{COOH}} \times P_{\mathrm{O}_{2}}}{1+k\left(P_{\mathrm{O}_{2}}+K_{3} \times P_{\mathrm{C}_{2} \mathrm{H}_{4}}+\text { negligibe adsorption terms } \ldots . .\right)}$.

For large $k$, these two equations can be approximated by Eqs. (21) and (22).

For the oxidation of $\mathrm{CO}$ to $\mathrm{CO}_{2}$ this occurs through adsorbed oxygen and adsorbed $\mathrm{CO}$ on a site denoted by $\mathrm{Z}$ such that

$\mathrm{Z}+\frac{1}{2} \mathrm{O}_{2} \rightleftarrows \mathrm{ZO}$

$2 \mathrm{ZO} \rightleftarrows \mathrm{ZO}_{2}+\mathrm{Z}$ 
$\mathrm{ZO}+\frac{1}{2} \mathrm{O}_{2} \rightleftarrows \mathrm{ZO}_{2}$

$\mathrm{CO}+\mathrm{Z} \rightleftarrows \mathrm{COZ}$

$\mathrm{COZ}+\mathrm{ZO}_{2} \rightarrow \mathrm{CO}_{2} \mathrm{Z}+\mathrm{ZO}(\mathrm{RDS})$

$\mathrm{CO}_{2} \mathrm{Z} \rightarrow \mathrm{CO}_{2}+\mathrm{Z}$ (fast)

$r_{10}=k \times k \frac{k_{10} \times P_{\mathrm{CO}} \times P_{\mathrm{O}_{2}}}{\left(1+k\left(P_{\mathrm{CO}}+K_{4} P_{\mathrm{O}_{2}}\right)\right)^{2}}$.

For large $k$ this equation can be approximated by Eq. (23).

The order of magnitude of the activation energies is similar to the values reported in the literature $[1,8,9]$. Large activation energy means that the reaction is favored at high temperature. Thus, it is noticed from the values of activation energy and from experimental results that higher temperature favors the formation of $\mathrm{CO}_{2}$ from oxidation of ethane.

Figures 3, 4 and 5 show the goodness of fit between the observed ethane conversion, $\mathrm{CO}_{2}$ yield and acetic acid yield and that calculated from the kinetic model. Reasonable fit is obtained for high conversion which would be of practical importance. For low conversion, the fit is slightly distorted possibly because inaccuracy in the experimental results.

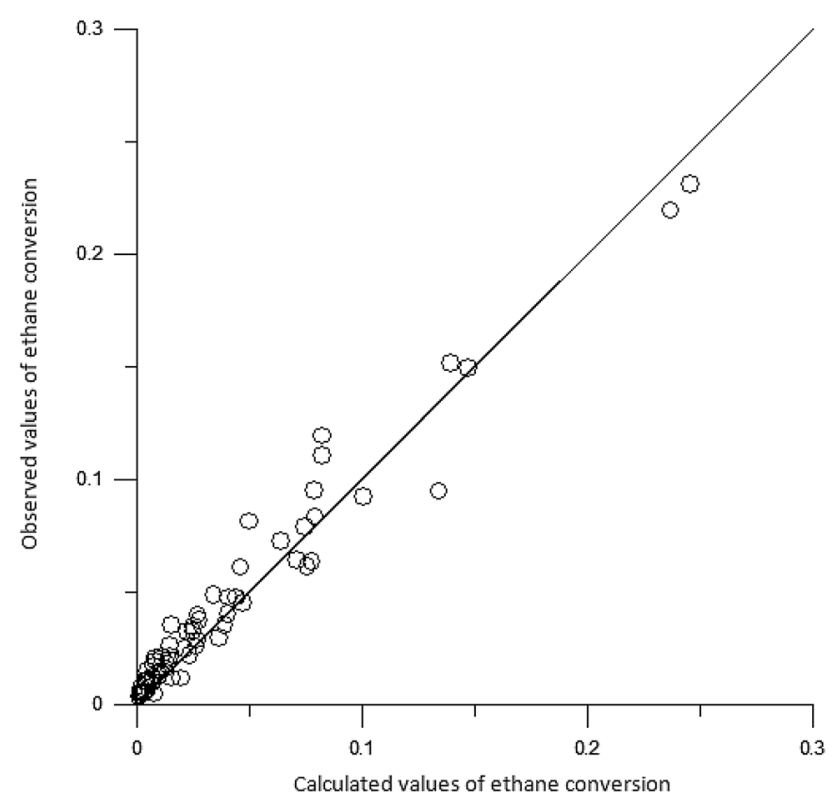

Fig. 3 Observed and calculated conversion for ethane partial oxidation

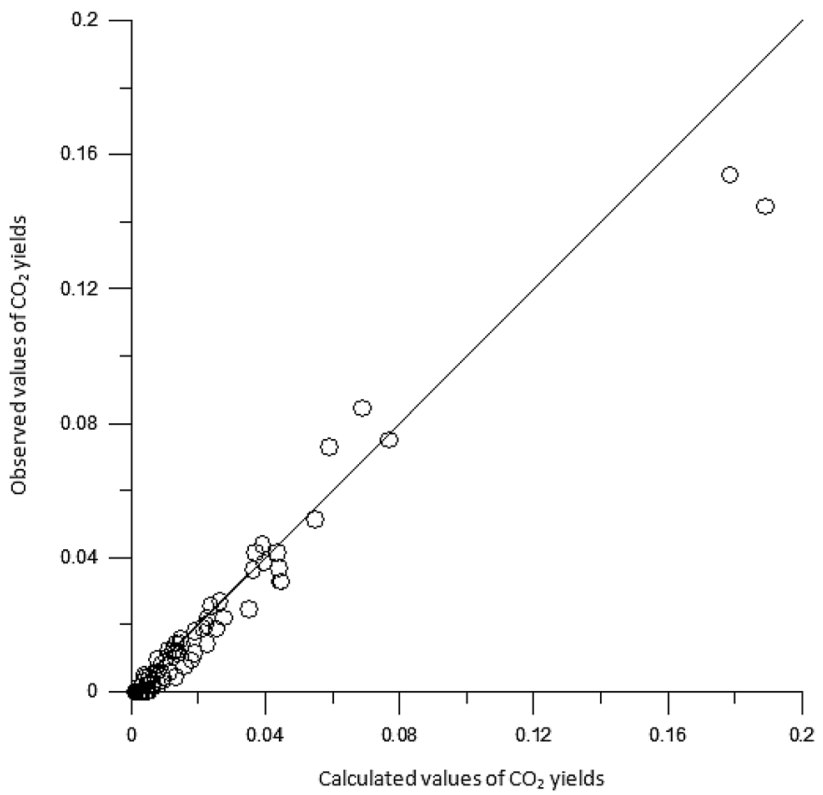

Fig. 4 Observed and calculated yield of $\mathrm{CO}_{2}$ for partial oxidation of ethane

\section{Conclusion}

Our kinetic model has a phenomenological and statistical significance. We assumed a general network, but found through model development and parameter estimation of model parameters that the significant reactions are ethane

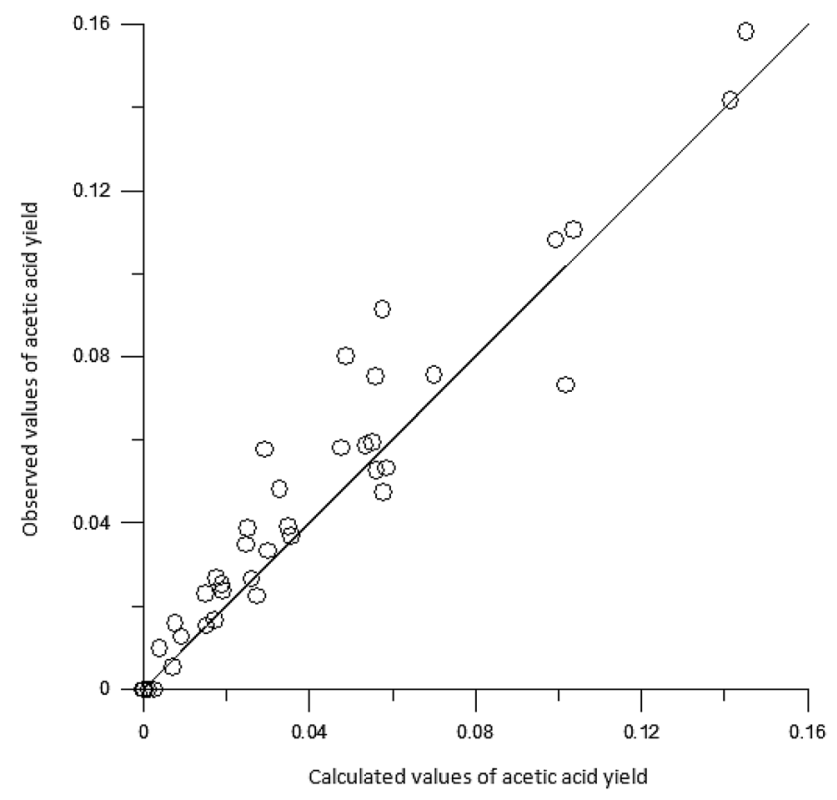

Fig. 5 Observed and calculated values of acetic acid yield for partial oxidation of ethane 
oxidation to ethylene and $\mathrm{CO}_{2}$, ethylene to acetic acid, $\mathrm{CO}$ and $\mathrm{CO}_{2}$, and $\mathrm{CO}$ to $\mathrm{CO}_{2}$. The analysis showed that ethane oxidation to acetic acid and $\mathrm{CO}$ is not significant. The reaction takes place on three sites, one for ethane oxidation to ethylene, the second for ethylene oxidation to acetic acid, $\mathrm{CO}$ and $\mathrm{CO}_{2}$, and the third for the oxidation of $\mathrm{CO}$ to $\mathrm{CO}_{2}$ In spite of reasonable acetic acid selectivity, there is still scope for catalyst improvement because of the high $\mathrm{CO}_{2}$ selectivity.

Future work can be directed towards deep understanding of all steps, such as ethylene oxidation, acetic acid oxidation, $\mathrm{CO}$ oxidation with these experiments carried out in the presence and absence of water vapor. The species which lead to the partial oxidation products should be identified.

Acknowledgements The authors acknowledge the financial support provided by King Abdul Aziz City for Science and Technology (KACST) for this research under Grant number AR-29-256.

Open Access This article is distributed under the terms of the Creative Commons Attribution 4.0 International License (http://creativeco mmons.org/licenses/by/4.0/), which permits unrestricted use, distribution, and reproduction in any medium, provided you give appropriate credit to the original author(s) and the source, provide a link to the Creative Commons license, and indicate if changes were made.

\section{References}

1. Thorsteinson EM, Wilson TP, Young FG, Kasai PH (1978) The oxidative dehydrogenation of ethane over catalysts containing mixed oxides of molybdenum and vanadium. J Catal 52:116-132

2. Fakeeha AH, Soliman MA, Al-Rashidy MO, Ibrahim AA (1999) Sensitivity analysis of oxydehydrogenation of ethane in fixed bed reactor. Afinidad 56(484):369-376

3. Fakeeha AH, Al-Zeghayer YS, Soliman MA (2001) Sensitivity analysis for partial oxidation of ethane in a fluidized bed reactor. JEAS 48(2):385-399

4. Al-Sherehy FA, Adris AM, Soliman MA, Hughes R (1998) Avoidance of flammability and temperature runaway during oxidative dehydrogenation using a distributed feed. Chem Eng Sci 53(23):3965-3976
5. Karim K, Mamedov E, Al-Hazmi MH, Fakeeha AH, Soliman MA, Al-Zeghayer YS, Al-Fatish AS, Al-Arify AA (2000) Catalysts for producing acetic acid from ethane oxidation, processes for making same and method of using same. US Patent No 6, 030, 920, Feb 29

6. Fakeeha AH, Fahmy YM, Soliman MA, Alwahabi SM (2000) A kinetic model for partial oxidation of ethane to acetic acid on promoted VPO catalyst. J Chem Technol Biotechnol 75:1160

7. Linke D, Wolf D, Dingerdissen U, Zey $\beta$ BS, Baerns M (2002) Catalytic partial oxidation of ethane to acetic acid over $\mathrm{Mo}_{1} \mathrm{~V}_{0.25}$ $\mathrm{Nb}_{0.12} \mathrm{Pd}_{0.0005} \mathrm{O}_{x}$ part I: catalyst performance and reaction mechanism. J Catal 205:16-31

8. Linke D, Wolf D, Dingerdissen U, Zey $\beta$ BS, Baerns M (2002) Catalytic partial oxidation of ethane to acetic acid over $\mathrm{Mo}_{1} \mathrm{~V}_{0.25}$ $\mathrm{Nb}_{0.12} \mathrm{Pd}_{0.0005} \mathrm{O}_{x}$ part II: kinetic modeling. J Catal 205:32-43

9. Rahman F, Loughlin KF, Al-Saleh MA, Saeed MR, Tukur NM, Hossain MM, Karim K, Mamedov A (2010) Kinetics and mechanism of partial oxidation of ethane to ethylene and acetic acid over MoV type catalysts. Appl Catal A Gen 375(1):17-25

10. Li X, Iglesia E (2008) Support and promoter effects in the selective oxidation of ethane to acetic acid catalyzed by $\mathrm{Mo}-\mathrm{V}-\mathrm{Nb}$ oxides. Appl Catal A Gen 334(1-2):339-347

11. Li X, Iglesia E (2008) Kinetics and mechanism of ethane oxidation to acetic acid on catalysts based on Mo-V-Nb oxides. J Phys Chem 112(38):15001-15008

12. Burch R, Swarnakar R (1991) Oxidative dehydrogenation of ethane on vanadium-molybdenum oxide and vanadium-niobiummolybdenum oxide catalysts. Appl Catal A Gen 70:129-148

13. Berlowitz PJ, Peden CHF, Goodman DW (1988) Kinetics of carbon monoxide oxidation on single-crystal palladium, platinum, and iridium. J Phys Chem 92:5213-5221

14. Hosten LH, Froment GF (1975) Parameter estimation in multiresponse models. Period Polytech Chem Eng 19:123-136

15. Al-Zeghayer YS, Al-Awadi AS, Jibril BY, Soliman MA, Al-Mayman S (2013) Partial oxidation of ethane to acetic acid on titania supported MoVNbPd catalyst. Asian J Chem 25:7979-7985

16. Al-Mayman S, Al-awadi AS, Al-Zeghayer YS, Soliman MA (2018) Partial oxidation of ethane to acetic acid using metallic Pd promoted MoVNb catalyst supported on titania. J Chem Soc Pak 40(1):76-88

Publisher's Note Springer Nature remains neutral with regard to jurisdictional claims in published maps and institutional affiliations. 